\title{
Speaking Performance and Anxiety Levels of Chinese EFL Learners in Face-to-Face and Synchronous Voice-based Chat
}

\author{
Yanqiu Chen, Shin Yi Chew \\ Universiti Malaya \\ Correspondence concerning this article should be addressed to Dr. Chew Shin Yi, Faculty of Languages \& \\ Linguistics, Universiti Malaya, 50603 Kuala Lumpur, Malaysia. E-mail: chewshinyi@um.edu.my
}

\begin{abstract}
In recent, mobile technology is experiencing a highly development, it is necessary to explore whether it holds the potential to boost EFL learners' language acquisition based on its instant messaging apps in synchronous voice chat (SVC) mode. With a focus on Chinese EFL learners, this study aimed to compare their speaking performance in SVC and face-to-face (F2F) chat modes. It also explored the relationship between learners' speaking performance and anxiety levels in these two chat modes which allow real-time communication. In this mixed methods study, WeChat instant messaging was used as the platform for SVC. Forty students from a public university in China participated in 4 chat sessions in SVC and F2F chat modes over 4 weeks. Quantitative data were collected through the oral scores of the participants' performance in the chat sessions and anxiety questionnaires. Then, qualitative data were obtained from a focus group interview. The findings revealed a significant difference in learners' speaking performance in SVC and F2F chat. Students' speaking performance outperformed in SVC chat compared to F2F chat. This could be linked to students' anxiety levels which were slightly higher in F2F chat. Despite that, most of the students preferred F2F chat to SVC chat due to the practicality of F2F chat. ${ }^{1}$
\end{abstract}

Keywords: speaking performance, foreign language anxiety, synchronous voice chat mobile learning

\section{Introduction}

Speaking is regarded as a social act which is crucial for people to communicate, exchange information, and build, as well as maintain longitudinal relationships with others. Thus, a good mastery of speaking skill would benefit learners' social engagement and academic achievement (Arung, 2016; Oruç \& Demirci, 2020). In the context of language learning and teaching, speaking is identified as the most challenging and complex skill compared to listening, reading, and writing skills (Rao, 2018). This is because speaking involves observation, complex meaning construction, and preparation of an utterance at the same time. This process requires learners to decide the content and the time and place of communication while taking into account the interlocutor's diverse cultural and social backgrounds (Burns, 2019; Burns \& Seidlhofer, 2002). Therefore, many learners often experience foreign-language anxiety (FLA), especially when the language used is not their first language and they are required to speak it in front of a group of people (Misqam \& Saidalvi, 2019).

In China, a majority of EFL learners regardless of age, proficiency levels or language background experience anxiety when they speak English. In Liu and Jackson's (2008) Foreign Language Anxiety survey among Chinese undergraduate students, more than one-third of the participants stated that they felt anxious in their language classroom and more than half were scared of public speaking. Another study by Landström (2015) also found that a majority of Chinese senior high school students suffered from language anxiety. In his study, the students felt most anxious when they had to speak English when their language teachers were present in the classroom. Due to anxiety, most learners often chose to stay silent and refused to participate in oral activities during language classes. This unwillingness to speak and tendency to keep silent further impeded their language development.

\footnotetext{
Dissertation information. The experiment data, data analysis and research instruments in this article are part of one of the author's master dissertation: Chen, Y. (2018). Speaking performance and anxiety levels of Chinese EFL learners in face-to-face and synchronous voice-based chat. [Unpublished master's dissertation]. Universiti Malaya.
} 
To make matters worse, Chinese EFL learners predominantly learn English in a context where the target language is seldom used, and the English classes are mainly teacher-centred and exam-oriented (Yang, Gamble \& Tang, 2012; Wang, 2014). This has caused speaking skill to be overlooked and the learners' speaking ability is relatively incompetent even though they have undertaken long-term English training. The lack of language interaction and oral practice in the classroom might have caused Chinese EFL students to have lower selfconfidence and higher anxiety towards speaking. In fact, a large number of Chinese students experience FLA in their language learning process, especially when they have to speak in front of a group of people. Woodrow (2006) even found Chinese learners to be more anxious than any other Asian students when conversing.

Based on the above-mentioned problems in speaking and learning environment, it is crucial to create a secure and comfortable environment for language learners to alleviate their English-speaking anxiety and practise spoken communication with confidence. As mobile technology becomes increasingly popular, this study investigates the potential of one of the main features of mobile applications, synchronous voice-based chat (SVC), in offering a conducive environment for language learners to practise and enhance their English speaking skills.

According to Jasim and Abuseileek (2015), SVC is defined as a type of chat system that allows people to communicate with others in real time using online voice messages. Some popular phone applications that allow SVC include WhatsApp, Telegram and WeChat. In China, WeChat has become the dominant multi-media platform for mobile-mediated communication (Gao et al., 2019; Qu et al., 2015; Wu, 2015). Therefore, it might provide a new way for learners to communicate in English using the multiple modes of text messaging, voice messaging, and moment sharing.

Even though several studies have explored learners' performance of vocabulary acquisition, repair moves and experience in the computer-mediated SVC environment, the quantity of published research on speaking anxiety in SVC chat mode is still meager (Bueno, 2013; Bueno, 2011; Jepson, 2005). Additionally, very few research has investigated the use of the WeChat instant messaging application tool and its effectiveness in improving speaking performance and lowering speaking anxiety within the Chinese context. Thus, there is a great need for more studies to explore the potential use of WeChat especially in developing Chinese EFL learners' speaking performance.

To better understand the affordances of SVC in terms of its impact on Chinese learners' anxiety level and speaking performance, its use in the WeChat application platform is compared to face-to-face (F2F). The research questions of this study are as follows:

1. To what extent do learners' speaking performances in face-to-face chat differ from synchronous voice chat experiences?

2. To what extent do learners' anxiety levels in face-to-face chat differ from synchronous voice chat experiences?

3. What is the relationship between learners' speaking performance and their anxiety levels in both face-toface and synchronous voice chat?

\section{Literature Review}

\section{Foreign Language Anxiety (FLA)}

Anxiety is one of the most influential factors that affect a learner's language development (Aydin, 2018). In 1986, Horwitz and Cope defined foreign language anxiety (FLA) as a distinct and complex form of anxiety which caused learners to have fear and negative emotional feelings when they are learning a language in a classroom setting. Similarly, MacIntyre and Gardner (1991) described FLA as the anxiousness and nervousness experienced by learners when using a target language which they are not competent yet. From the above mentioned definitions, FLA can be also categorized under situation-specific anxiety (Aydin, 2008; Horwitz, 2001).

Anxiety may facilitate or hinder the language learning process (Aydin, 2018). To date, research findings generally show that anxiety negatively impacts foreign language learning process (Aydin, 2018; Ellis, 2012). As 
explained by MacIntyre (1995, p.96), 'nervous students are focused on both the task at hand and their reactions to it...[they] will not learn as quickly as relaxed students'.

This is in accordance with Krashen's affective filter hypothesis (1985) which proposed that learning could only occur when a learner's affective filter is not blocking the process. People with low motivation, low selfconfidence, and/or high anxiety levels tend to have higher affective filters, which hinders input and acquisition (Ellis, 2013). In this regard, his main tenets are:

- A raised affective filter can block input from reaching Language Acquisition Device (LAD).

- A lowered affective filter allows the learning input to "strike deeper" and the second language to be acquired.

- The affective filter is responsible for individual variation in second language acquisition,which means it is a variable that affects second language acquisition.

Based on Krashen's affective filter hypothesis (1985), anxiety can act as a barrier or "mental block" which hinders comprehensible input and language development. In consistence with the affective filter hypothesis, past studies in general have posited a negative relationship between anxiety and learning achievement (Cakici, 2016; Salehi \& Marefar, 2014; Teimouri, Goetze \& Plonsky, 2019). However, there are also studies such as Pichette (2009) and Zheng and Cheng (2018) which claimed that there was no relationship between anxiety and language achievement. In view of the inconsistent findings and a lack of attention paid to the use of technology (Aydin, 2018), there is a need for this study to explore how foreign language anxiety affects EFL learners' language performance in different settings, specifically the traditional face-to-face environment and technology-mediated environment which affords SVC. In this study, the learners' FLA in these different chat modes is explored with Krashen's affective filter hypothesis (1985) functioning as the theoretical basis.

\section{Synchronous Voice-Based Chat (SVC)}

SVC is believed to resemble face-to-face (F2F) communication more closely than text chat as it involves learners articulating their words rather than typing them out (Jung, 2018). In addition, SVC allows learners to have oral interactions in real-time. Participants could share ideas, answer messages, and relay other information in SVC (Sukrutrit, 2018). However, the response time in SVC could be slightly slower than F2F since it is mediated by internet connection and relayed with minimal time lag (Sukrutrit, 2018).

There are a few studies which have compared learners' performance in these similar but different chat modes like F2F, text chat and SVC. For instance, Jepson (2005) compared learners' repair moves in text and voice chat sessions. He found that participating learners in an SVC environment generated a higher number of pronunciation-related repair moves in their oral interactions. This study thus predicted the potential usefulness of SVC in improving learners' speaking performance, specifically in pronunciation. However, there is a need for empirical data to confirm the speaking achievements.

Baralt and Gurzynski-Weiss (2011) also explored learners' performance in different settings. Specifically, they examined learners' level of anxiety in F2F and synchronous text-based chat modes and found learners to be more anxious in F2F communication. This could be due to learners' need to respond quickly and the fear of making mistakes in front of others. In contrast, learners were found to be less anxious in text-based chat as they have more time to prepare their answers and need not face the people they are communicating with. Interestingly, compared to face-to-face communication, anxiety was not significantly lower in the CMC setting where learners engaged in synchronous text-based chat. One of the plausible reasons could be the small number of participants (25 participants) involved in this study.

Andújar-Vaca and Cruz-Martínez (2017) recruited 80 participants in their study and allowed them to choose among synchronous or asynchronous, text-based or voice-based communication methods on the WhatsApp platform. Learners' speaking performance was assessed according to Hughes' (2003) general proficiency speaking scale. Significant improvements in speaking proficiency were found among students who were in synchronous text-chat and voice-chat groups. The findings of this study suggests that synchronous chat may be more effective than asynchronous chat in improving learners' speaking skills. Unfortunately, it is unclear whether synchronous text chat or voice chat is more effective in enhancing learners' speaking performance. 
To find out if synchronous text chat or voice chat is more advantageous, Ehsan et al. (2021) and Satar and Özdener (2008) have conducted experiments to assess the impact of chat settings on learners' speaking proficiency as well as levels of anxiety. The findings showed that students' speaking proficiency increased in both chat groups. However, learners' anxiety levels were lower in the text chat group. This result could be because text chat, while similar to spoken language, does not require the use of articulators. For this reason, their assessment of speaking performance through a comparison of non-vocal text chat and voice chat might not be convincing. A study which compares learners' anxiety level and speaking performance in face-to-face and SVC may reveal a better understanding of learners' speaking performance in different chat environments.

It is also worthy to note that York, Shibata Tokutake and Nakayama (2021) have recently compared the impact of voice chat, video chat and virtual reality (VR) chat on thirty Japanese students' FLA. All these three modes were able to reduce participants' FLA but the differences were not statistically significant.On the other hand, Bueno (2011) and Kim (2017) found learners to show positive attitudes towards SVC. These learners did not only experience lower level of anxiety and stress but also showed statistically significant improvement in their speaking tests. This positive findings about SVC prompts the current study to further investigate the potential of synchronous voice chat by comparing it to face-to-face communication.

Overall, studies have found advantages in using synchronous voice-based communication to improve learners' oral performance such as learners' pronunciation-related repair moves (Jepson, 2005), speaking proficiency (Andújar-Vaca \& Cruz-Martínez, 2017, Bueno, 2011; Eshan et al., 2021; Kim, 2017; Satar \& Özdener, 2008), speaking fluency and vocabulary acquisition (Jaramillo Chérrez, 2007). However, there are studies that have not found significant improvement in learners' speaking ability (e.g., Baralt \& Gurzynski-Weiss, 2011; Bueno, 2011; Seferoglu, 2007). As for the differences of learners' anxiety levels in SVC, text chat and face-to-face chat, the results are inconsistent (Baralt \& Gurzynski-Weiss, 2011; Bueno, 2011; Eshan et al., 2021; Kim, 2017).

For these reasons, more studies are needed to explore the relationship between anxiety and language performance in different environments. The present study aims to fill the gap in current literature by examining EFL learners' speaking performances in relation to aspects such as pronunciation, grammar, and fluency within the context of China by comparing the use of SVC in WeChat application with F2F communication. Since anxiety levels may affect learners' speaking performance, the present study also looked into Chinese EFL learners' anxiety while they practise their speaking skills in F2F and SVC conditions.

\section{Methodology}

\section{Research Design}

This study applied a mixed-methods approach. As Creswell and Guetterman (2019) suggest, a mixed-method study allows researchers to answer questions in depth and present a more comprehensive research result. Thus, it can provide a better understanding of the problems compared to either a quantitative or qualitative method.

In this study, an explanatory sequential design was employed. Based on this design, quantitative data were first collected from a quasi-experiment which involved participants interacting in both face-to-face and SVC environments as well as two anxiety questionnaires which elicited learners' anxiety levels in different chat conditions. Then, qualitative data were gathered from a focus group interview to provide supporting details (Creswell \& Guetterman, 2019).

\section{Participants}

To select the participants, a background survey was administered to the first-year students from the School of Foreign Languages at a public university in China. In using the background survey, 40 first-year students who were familiar with WeChat and possessed intermediate level of English language proficiency were selected to participate in this study. All the participants (female $=39$, male $=1$ ) were Chinese native speakers majoring in English and their age ranged from 19 to 21 years old.All these 40 students were randomly grouped into Group 1 and Group 2. These matched-samples groups (Group 1 and Group 2) experienced both chat conditions (F2F vs SVC) alternately according to the schedule in Table 1 (see Procedure). 


\section{Research Instruments}

\section{Background Survey}

According to Mackey and Gass (2015), a background survey is widely used in educational research in order to match the participants to the research focus. In this study, a background survey was administered to select participants with similar characteristics.

The background survey of this study consisted of three parts. Part one elicited participants' basic demographic information such as name, age, gender, and email address. Part two contained questions about participants' English language ability (overall scores of both their entrance and oral exams) while part three asked learners about their usage frequency of WeChat.

Based on the learners' response in the background survey, the researcher selected 40 students whose English was at the Intermediate Level (a score between 90 and 120 out of 150 based on their university entrance exam), and who consistently used WeChat on a frequent, daily basis.

\section{Oral Tasks and Scales}

Because both decision-making and problem-solving tasks have been identified as ideal triggers to elicit learners' oral communication (Tam, 2009), the present study selected two decision-making tasks, (Task A, Task B); and two problem-solving tasks, (Task C, Task D). The oral tasks were adapted from studies by Tam (2009) and Chérrez (2007).

Task A and Task B were similar in their scope of asking participants to plan two different kinds of tours according to the given criteria, using dyad discussion. In Tasks $\mathrm{C}$ and $\mathrm{D}$, participants had to explain their understanding of the background causes and possible solutions to two current social issues, (unemployment and the leftover or unmarried women phenomenon). The topics were chosen because they were of interest to students and were widely discussed in Chinese society. In this way, it was ensured that all participants would have prior knowledge about the assigned questions.

Hughe's (2003) oral assessment scale was used in this study. Based on the marking guideline, the participants' speaking performances were determined by totaling the points from five categories (grammar, fluency, pronunciation, organization, and vocabulary). The possible scores in each category ranged from 6 to 36 .

\section{Anxiety Questionnaires}

In order to identify the differences between learners' anxiety levels in F2F and SVC settings, anxiety questionnaires from Satar and Özdener's (2008) study were adapted. Each questionnaire contained 7 questions dealing with students' anxious feelings in F2F and SVC chat environments, respectively. Questionnaire 1 was for F2F chat while Questionnaire 2 was for those involved in SVC.

In order to match the questionnaires with the current research focus and context, the researcher changed the phrase "text chat" of Satar and Özdener's (2008) questionnaire to "face-to-face chat;" and "Foreign language" to "English." Some questions that had less relevance to students' anxiety and speaking were not used in this study. The researcher also modified the 3-point Likert scale to a 5-point Likert scale to increase response accuracy and provide participants more options to present their opinions. Since each questionnaire consisted of seven questions regarding learners' anxiety, the scores ranged from 7 to 35 , according to the five Likert-point scale.

To ensure that the modified SVC and F2F anxiety questionnaires were suitable and reliable, a pilot study was conducted on 6 first-year students from the same university who shared the similar characteristics as the participants of this research (intermediate level of language proficiency, frequent users of WeChat, 19 to 20 years old). The Cronbach's alpha value for the adapted SVC anxiety questionnaire was $\alpha=0.75$, and the adapted F2F anxiety questionnaire was $\alpha=0.8$. 


\section{Procedure}

Before the experiment, a briefing session was held to explain the experiment and to distribute consent forms and background surveys to the first-year EFL university students. Based on the background survey, 40 participants who possessed similar pre-identified characteristics (intermediate level of English language proficiency, frequent users of WeChat, similar age group) were selected to participate in this study. These selected participants were randomly divided into two matched-samples groups; Group 1 and Group 2. Each group consisted of 20 participants as the language lab that was used to record F2F chat could only accommodate a maximum of 20 students at one time. The schedule of the oral tasks is as follows:

\section{Table 1}

Schedule for Oral Tasks

\begin{tabular}{lclc}
\hline Session & Chat mode & Group & Oral Tasks \\
\hline 1 & F2F & Group 1 & task A - break - task C \\
2 & SVC & Group 2 & task A - break- task C \\
3 & SVC & Group 1 & task B - break- task D \\
4 & F2F & Group 2 & task B - break - task D \\
\hline
\end{tabular}

In sessions 1 and 3, Group 1 finished two F2F tasks and two SVC tasks consecutively. In sessions 2 and 4, Group 2 finished the two SVC oral tasks and then the two F2F tasks.

In F2F setting, the participants sat in separate areas provided by the faculty at the lab. This prevented external interruptions. For the SVC dyads, each pair created a WeChat group with the researcher who was not their instructor, so that she could help to coordinate the chat activities. The participants then held their chats within their own WeChat group, and voice messages were automatically stored in their mobile phones. No limitations were placed on where they could be during the SVC chat, except that the environment needed to be quiet enough for a clear recording.

Since decision-making and problem-solving tasks have been identified as ideal triggers to elicit learners' oral communication (Jaramillo Chérrez, 2007; Tam, 2009), the present study selected two decision-making tasks (Task A and Task B) and two problem-solving tasks (Task C and Task D) as speaking activities. Task A and Task $B$ required participants to plan two different kinds of tours according to the given criteria. On the other hand, participants had to explain their understanding of the current social issues and find possible solutions in Tasks C and D. All these tasks were adapted from studies by Tam (2009) and Jaramillo Chérrez (2007).

The researcher handed out the task sheets to the participants five minutes before the start of the activity. This was done so that they could read the instructions and be prepared. Then, each pair was given 15 minutes to complete an oral task, either face-to-face or SVC. After each task, the participants would then take a 15-minute break and continue with a different oral task but still within the same interactional setting. Before the end of each session, participants were required to answer an anxiety questionnaire.

Participants' speaking performances under the F2F and SVC conditions were assessed by two experienced colleagues. One of them is a lecturer with more than 30 years of teaching and evaluation experience in the field of advanced oral English for Chinese EFL learners. The other assessor is an EFL teacher with more than ten years of overseas teaching experience. The participants' oral scores were marked in using Hughe's (2003) oral assessment scale. The scorings of these two experts showed an inter-rater reliability of 0.9 , which indicated their consistencies and similarities in marking.

Lastly, after the 4-week experiment, a focus group interview was conducted among five willing participants to gain further insight into the participants' experience of anxiety in both the F2F and SVC environments. The participants (3 from group 1, 2 from group 2) shared their opinions and feelings about going through the oral tasks within the two different chat conditions. The interview was conducted in Mandarin, the participants' mother tongue. The video transcript of this interview was then translated into English and the translation was 
checked for accuracy by an experienced and qualified English lecturer. The English translation was then utilized for the qualitative analysis.

\section{Data Analysis}

To find out the differences of learners' speaking performance in F2F and SCV, the participants' speaking performances were firstly determined by totaling the points from the five parameters (pronunciation, grammar, fluency, vocabulary, and comprehension). Then, the researcher performed a paired-samples t-test using SPSS version 25 software to determine whether there was a significant difference between learners' speaking performance when they were involved in F2F and SVC chat conditions. In this study, the Kolmogorov-Smirnova statistic indicated a normal distribution of the data collected from participants' speaking performance in SVC chat (Sig. $=.143$ ) and F2F chat (Sig. $=.200 *$ ). The speaking anxiety levels were also normally distributed in SVC chat (Sig. $=.075$ ) and F2F chat (Sig. $=.200 *$ ). The normality test indicated a normal distribution for the data collected from learners' speaking and anxiety levels. Thus, the parametric statistics (the paired-samples t-test) was used in this study.

The participants' anxiety levels were generated from the anxiety questionnaires concerning their emotions in F2F and SVC conditions. Since each questionnaire consisted of seven questions regarding learners' anxiety, the scores ranged from 7 to 35, according to the five Likert-point scale. A higher score indicates a higher level of anxiety. A paired-samples t-test was run to check whether there was a significant difference in learners' anxiety levels between the two chat modes (F2F and SVC).

After that, a Pearson Correlation Test was conducted on the participants' oral scores and anxiety score to understand the relationship between learners' speaking performance and anxiety levels in F2F and SVC mode.

To gain insights into learners' speaking performance and anxiety level in different chat conditions, the data gathered from the focus group interview was analysed using open coding strategies. Relevant themes from the interview transcripts were identified and coded.

\section{Results and Discussions}

\section{Learners' Speaking Performance in Face-to-face Chat and Synchronous Voice Chat}

To answer the first research question of whether learners' speaking performance in F2F chat differ from SVC chat, a paired-samples T-test was performed. The results are shown in Table 2.

Table 2

Differences of Learners' Speaking Performance in F2F and SVC

\begin{tabular}{|c|c|c|c|c|c|c|c|c|}
\hline & \multirow[b]{3}{*}{$\begin{array}{l}\text { Chat } \\
\text { mode }\end{array}$} & \multicolumn{7}{|c|}{ Paired Differences } \\
\hline & & & \multicolumn{6}{|c|}{ 95\% Confidence Interval of the Difference } \\
\hline & & $\begin{array}{c}\text { Mean } \\
\text { decrease }\end{array}$ & Lower & Upper & $t$ & $d f$ & $\begin{array}{c}\text { Sig. } \\
\text { (2-tailed) }\end{array}$ & $\begin{array}{c}\text { Eta } \\
\text { Squared }\end{array}$ \\
\hline Pronunciation & $\begin{array}{l}\text { SVC } \\
\text { F2F }\end{array}$ & .575 & .315 & .835 & 4.473 & 39 & .000 & .35 \\
\hline Grammar & $\begin{array}{l}\text { SVC } \\
\text { F2F }\end{array}$ & .575 & .385 & .765 & 6.119 & 39 & .000 & .49 \\
\hline Vocabulary & $\begin{array}{l}\text { SVC } \\
\text { F2F }\end{array}$ & .675 & .420 & .930 & 5.356 & 39 & .000 & .42 \\
\hline Fluency & $\begin{array}{l}\text { SVC } \\
\text { F2F }\end{array}$ & .825 & .555 & 1.095 & 6.183 & 39 & .000 & .50 \\
\hline Comprehension & $\begin{array}{l}\text { SVC } \\
\text { F2F }\end{array}$ & 1.550 & 1.300 & 1.800 & 12.523 & 39 & .000 & .80 \\
\hline Overall scores & $\begin{array}{l}\text { SVC } \\
\text { F2F }\end{array}$ & 3.425 & 2.649 & 4.20 & 18.924 & 39 & .000 & .90 \\
\hline
\end{tabular}


According to Table 2, there was a statistically significant difference between the learners' oral performance in SVC and F2F chat in each assessed component, (pronunciation, grammar, vocabulary, fluency, and comprehension).

In the participants' pronunciation performance, there was a statistically significant difference in the pronunciation scores of participants who engaged in SVC chat $(\mathrm{M}=3.78, \mathrm{SD}=.77)$ and $\mathrm{F} 2 \mathrm{~F}$ chat $(\mathrm{M}=3.20, \mathrm{SD}=.91)$, $\mathrm{t}(39)=4.473, p<.0005$ (two-tailed). The participants achieved higher pronunciation scores in SVC than in F2F chat. The mean decrease in overall scores was .575 with a $95 \%$ confidence interval ranging from .315 to .835 . The eta squared statistic (.35) indicated a large effect size. This finding is in congruence with Jepson (2005) who found learners to have better pronunciation in SVC than in F2F chat.

Looking at the participants' performance in grammar, there was a statistically significant difference in learners' grammar scores when they took part in SVC chat $(\mathrm{M}=4.08, \mathrm{SD}=.53)$ and $\mathrm{F} 2 \mathrm{~F}$ chat $(\mathrm{M}=3.5, \mathrm{SD}=.56), \mathrm{t}(39)=6.119$, $p<.0005$ (two-tailed). The participants achieved higher grammar scores in SVC than in F2F chat. The mean decrease in overall scores was .575 with a $95 \%$ confidence interval ranging from .385 to .765 . The eta squared statistic (.49) indicated a large effect size. As explained by Participant No. 39 in the following extract, learners' scores in grammar and pronunciation could be better in SVC as they have the time to pay attention to these aspects.

In SVC, my attention could be placed too much on grammar and pronunciations.

(Participant No. 39)

Apart from pronunciation and grammar, the participants' vocabulary performance also showed a statistically significant difference when they participated in SVC chat $(M=3.80, S D=.61)$ and $F 2 F$ chat $(M=3.13, S D=.77), t$ $(39)=5.356, p<.0005$ (two-tailed). Similar to Chérrez (2007), the participants in this study achieved higher vocabulary scores in SVC than in F2F chat. The mean decrease in overall scores was .675 with a $95 \%$ confidence interval ranging from .420 to .930 . The eta squared statistic (.42) indicated a large effect size. SVC may be more beneficial in allowing learners to explore new vocabularies as expressed by Participant 39 in the interview session:

While I think SVC would be more helpful. F2F conversations merely depend on the extent of our vocabulary. If we don't have enough words to say in face to face, the conversations cannot continue. In contrast, SVC would be a driving force for us to explore some new words, materials while chatting. Therefore, our knowledge can be expanded in SVC.

(Participant No. 39)

When it comes to the participants' speaking fluency, there was also a statistically significant difference in the fluency scores of SVC chat $(\mathrm{M}=4.28, \mathrm{SD}=.56)$ and $\mathrm{F} 2 \mathrm{~F}$ chat $(\mathrm{M}=3.45, \mathrm{SD}=.78), \mathrm{t}(39)=6.183, \mathrm{p}<.0005$ (two-tailed). In line with Chérrez (2007), the participants were found to achieve higher fluency scores in SVC than in F2F chat. The mean decrease in overall scores was .825 with a $95 \%$ confidence interval ranging from .555 to 1.095 . The eta squared statistic (.50) indicated a large effect size. The following excerpts from Participants 12 and 27 further illuminates the challenges faced by learners in face-to-face chat which may have in turn affected their fluency scores.

I think the challenges in F2F would be the reaction time and vocabulary problems.

(Participant No. 12)

In F2F, limited vocabulary affects our speaking performance as our expressions could not go indepth.

(Participant No. 27)

In SVC chat $(\mathrm{M}=5.00, \mathrm{SD}=.00)$ and $\mathrm{F} 2 \mathrm{~F}$ chat $(\mathrm{M}=3.45, \mathrm{SD}=.78), \mathrm{t}(39)=12.523, p<.0005$ (two-tailed), the participants' comprehension scores also showed a statistically significant difference. The participants' achieved higher comprehension scores in SVC than in F2F chat. The mean decrease in overall scores was 1.55 with a 95\% confidence interval ranging from 1.30 to 1.80 . The eta squared statistic $\left(\eta^{2}=.80\right)$ indicated a large effect size.

In conclusion, there was a statistically significant difference in the overall scores of SVC chat $(\mathrm{M}=20.93$, $\mathrm{SD}=1.62)$ to $\mathrm{F} 2 \mathrm{~F}$ chat $(\mathrm{M}=17.5, \mathrm{SD}=2.65)$, $\mathrm{t}(39)=18.924, p<.0005$ (two-tailed). In other words, the participants' 
achieved higher scores of speaking in SVC than in F2F chat. The mean decrease in overall scores was 3.425 with a 95\% confidence interval ranging from 2.649 to 4.20 . The eta squared statistic (.90) indicated a large effect size.

Overall, the findings showed that learners' speaking performance in pronunciation, grammar, vocabulary, fluency, and comprehension was better in SVC than in F2F chat. One of the reasons could be that SVC chat requires learners to speak with greater accuracy than F2F chats where speakers can rely on other cues for mutual comprehension (Andújar-Vaca \& Cruz-Martínez, 2017). However, it is interesting to find that the participants in this study still prefer F2F chat, even though they have better performance in all the 5 parameters of speaking in SVC chat. This could be due to learners' individual differences such as their personality, preferred learning styles and strategies (Chew \& Ng, 2021).

\section{Learners' Anxiety Levels in Face-to-face chat and Synchronous Voice Chat}

To find out learners' anxiety levels in SVC and F2F chat, a paired-samples T-test was performed. The results are shown below in Table 3 .

\section{Table 3}

Difference of Leaners' Anxiety levels in F2F and SVC

\begin{tabular}{|c|c|c|c|c|c|c|c|}
\hline & & \multicolumn{6}{|c|}{ Paired Differences } \\
\hline & & & \multicolumn{5}{|c|}{ 95\% Confidence Interval of the Difference } \\
\hline & $\begin{array}{l}\text { Chat } \\
\text { mode }\end{array}$ & $\begin{array}{c}\text { Mean } \\
\text { decrease }\end{array}$ & Lower & Upper & $\boldsymbol{t}$ & $d f$ & $\begin{array}{c}\text { Sig. } \\
\text { (2-tailed) }\end{array}$ \\
\hline Anxiety levels & $\begin{array}{l}\text { SVC } \\
\text { F2F }\end{array}$ & -3.37 & -4.904 & -1.846 & -4.465 & 39 & .000 \\
\hline
\end{tabular}

According to Table 3, there was a statistically significant difference in learners' anxiety level in SVC chat $(\mathrm{M}=18.70, \mathrm{SD}=4.858)$ and $\mathrm{F} 2 \mathrm{~F}$ chat $(\mathrm{M}=22.08, \mathrm{SD}=5.322), \mathrm{t}(39)=-4.465, p<.0005$ (two-tailed). The eta squared statistic (.33) indicated a large effect size. This indicates that the participants were less anxious in synchronous voice-based chat. There are a few reasons why participants felt less anxious in SVC. The reasons shared by the interview respondents are as follows:

In using SVC, I had a short time to check for proper words and prepare quickly. This made me feel safe.

(Participant No. 11)

SVC chat made me feel less anxious in speaking as I didn't feel there was a rush to finish the speaking tasks.

(Participant No. 40)

In line with Kim (2017), the Chinese EFL learners were less anxious in SVC as they could be more prepared in the online setting and they were less worried about making mistakes since they could not see others' reactions. In addition, the learners could cancel their voice messages that were not good enough and try again. This increased their confidence in the oral tasks.

Details of participants' response to the items in anxiety questionnaires are presented in Table 4. 
Table 4

Findings from Anxiety Questionnaire $(N=40)$

\begin{tabular}{|c|c|c|c|c|c|c|}
\hline Item & $\begin{array}{l}\text { Chat } \\
\text { Mode }\end{array}$ & $\begin{array}{c}S D \\
\%\end{array}$ & $\begin{array}{l}D \\
\%\end{array}$ & $\begin{array}{l}N A D \\
\%\end{array}$ & $\begin{array}{l}A \\
\%\end{array}$ & $\begin{array}{c}S A \\
\%\end{array}$ \\
\hline \multirow{2}{*}{$\begin{array}{l}\text { 1. The fact that we were completing the activities using F2F / SVC } \\
\text { chat caused communication problems. }\end{array}$} & F2F & 2.5 & 35 & 25 & 37.5 & 0 \\
\hline & SVC & 7.5 & 45 & 37.5 & 10 & 0 \\
\hline \multirow{2}{*}{$\begin{array}{l}\text { 2. The fact that we were completing the activities using F2F / SVC } \\
\text { chat made it difficult to think before I said something }\end{array}$} & F2F & 7.5 & 27.5 & 22.5 & 37.5 & 5 \\
\hline & SVC & 10 & 57.5 & 20 & 10 & 2.5 \\
\hline \multirow{2}{*}{$\begin{array}{l}\text { 3. Because we were completing the activities using F2F/ SVC chat, I } \\
\text { was worried about my pronunciation. }\end{array}$} & F2F & 2.5 & 17.5 & 20 & 37.5 & 22.5 \\
\hline & SVC & 10 & 37.5 & 17.5 & 27.5 & 7.5 \\
\hline \multirow{2}{*}{$\begin{array}{l}\text { 4. It frightened me when I didn't understand what my partner was } \\
\text { saying by F2F/ SVC chat. }\end{array}$} & F2F & 17.5 & 17.5 & 22 & 37.5 & 2.5 \\
\hline & SVC & 10 & 20 & 17.5 & 45 & 7.5 \\
\hline \multirow{2}{*}{$\begin{array}{l}\text { 5. Even if I was well prepared for speaking tasks in foreign class, I felt } \\
\text { anxious about having F2F / SVC chat with my partner. }\end{array}$} & F2F & 12.5 & 32.5 & 12.5 & 35.5 & 7.5 \\
\hline & SVC & 12.5 & 60 & 12.5 & 15 & 0 \\
\hline \multirow{2}{*}{$\begin{array}{l}\text { 6. I feared to pronounce words incorrectly when I had F2F / SVC chat } \\
\text { with my partner. }\end{array}$} & F2F & 10 & 17.5 & 20 & 47.5 & 5 \\
\hline & SVC & 12.5 & 25 & 25 & 27.5 & 10 \\
\hline \multirow{2}{*}{$\begin{array}{l}\text { 7. I felt nervous when I couldn't express myself in English in front of } \\
\text { my partner by F2F / SVC. }\end{array}$} & F2F & 7.5 & 12.5 & 20 & 30 & 30 \\
\hline & SVC & 7.5 & 22.5 & 35 & 22.5 & 12.5 \\
\hline
\end{tabular}

Note. $\mathrm{SD}=$ Strongly Disagree; $\mathrm{D}=$ Disagree; $\mathrm{NAD}=$ Neither Agree nor Disagree; $\mathrm{A}=$ Agree; $\mathrm{SA}=$ Strongly Agree

With reference to item $1,37.5 \%$ of participants responded that F2F chat caused communication problems. However, only $10 \%$ of them faced the same problems in SVC chat.

Referring to item 2, more participants (67.5\%) stated that they had no difficulty in thinking before talking in SVC chat. For items 3 and 6, more participants were worried about their pronunciation in F2F chat (60\%) than in SVC (35\%). They feared wrong pronunciation in F2F chat (52.5\%) more than in SVC chat (37.5\%).

In contrast, findings from questionnaire item 4 show that $52.5 \%$ felt frightened of not understanding their partners in SVC chat, compared to 39.5\% of the participants in F2F chat. This could be due to technological concerns about faulty connections and poor sound quality when using SVC. In addition, face-to-face communication could facilitate better understanding compared to SVC since it provides non-verbal cues such as body language and facial expressions, as illustrated in the following excerpt:

We had many other ways to help us express meaning that are only available when speaking F2F... Even though we might not express ourselves with proper words, I could also understand my partner through her facial expressions and body languages.

(Participant No. 39)

Nonetheless, the participants generally showed a preference for SVC chat. As shown in items 5 and 7, only $15 \%$ of the students felt anxious in SVC when they were prepared, compared to the 35.5\% in F2F chat. Likewise, a higher percentage of participants felt nervous about expressing themselves in F2F chat (60\%) than in SVC (34.5\%). This scenario is exemplified by Participant 11 in the following excerpt.

I felt a bit nervous in F2F as I could not express myself accurately in the short time. Also, I felt upset that my speaking sometimes was not understandable for my partner.

(Participant No. 11)

All in all, there were higher percentages of participants who felt more anxious in F2F chat than in SVC. This was because the face-to-face setting made them more worried of not being able to express themselves clearly and pronounce their words accurately. This finding is in line with the study of Ellis (2012) who found that learners tend to be more bothered by their pronunciation and were more afraid of getting negative comments from others in face-to-face interactions. It is also interesting to note that the feeling of anxiety did not only occur in F2F communication but also in SVC as the participants in this study mentioned that they were apprehensive about being misunderstood since the facial expressions and body languages were missing in SVC. 
The Relationship between Learners' Speaking Performance and their Anxiety Levels in Face-to-face and Synchronous Voice Chat

Pearson Correlation Coefficient was conducted to investigate the relationship between learners' speaking performances and their anxiety levels in different chat conditions. The results are shown in Table 5 and Table 6.

\section{Table 5}

Correlations between Speaking Performance and Anxiety Levels in F2F Chat

\begin{tabular}{llcc}
\hline & & $\begin{array}{c}\text { Total oral scores } \\
\text { of F2F chat }\end{array}$ & $\begin{array}{c}\text { Total anxiety scores } \\
\text { of F2F chat }\end{array}$ \\
\hline Total oral scores of F2F chat & Pearson Correlation & 1.000 & $-.428^{* * *}$ \\
& Sig. (2-tailed) & & .006 \\
& $\mathrm{~N}$ & 40 & 40 \\
Total anxiety scores of F2F chat & Pearson Correlation & $-.428^{* * *}$ & 1.000 \\
& Sig. (2-tailed) & .006 & \\
& $\mathrm{~N}$ & 40 & 40 \\
\hline
\end{tabular}

** Correlation is significant at the 0.01 level (2-tailed).

As shown in Table 5, a medium negative correlation was found between the two variables, $\mathrm{r}=-.428^{* * *}, \mathrm{n}=40, p<$ .0005 . This means that higher levels of anxiety were associated with lower scores of speaking performance in the F2F chat.

Table 6

Correlations between Speaking Performance and Anxiety Levels in SVC

\begin{tabular}{llcc}
\hline & & $\begin{array}{c}\text { Total oral scores } \\
\text { of SVC }\end{array}$ & $\begin{array}{c}\text { Total anxiety scores } \\
\text { of SVC }\end{array}$ \\
\hline Total oral scores of SVC & Pearson Correlation & 1.000 & -.110 \\
& Sig. (2-tailed) & & .498 \\
& N & 40 & 40 \\
Total anxiety scores of SVC & Pearson Correlation & -.110 & 1.000 \\
& Sig. (2-tailed) & .498 & \\
& $\mathrm{~N}$ & 40 & 40 \\
\hline
\end{tabular}

** Correlation is significant at the 0.01 level (2-tailed).

Table 6 presents the correlations found between the students' speaking performances and anxiety levels in the SVC chat mode.In this case, there was only a small negative correlation between the two variables, $r=-.110$, $\mathrm{n}=40, p<.0005$. While a higher level of anxiety was associated with lower scores of speaking performance in SVC chat, the strength of the negative correlation was small ( $\mathrm{r}=-.110)$. Since the negative correlation was stronger in F2F chat, $(r=-.428)$ than in SVC chat, $(r=-.110)$, the F2F chat environment might have a stronger influence than SVC chat environment.

In sum, there was a negative correlation between the learners' levels of anxiety and their speaking performance in both F2F and SVC conditions. The participants attributed their lower levels of anxiety during SVC chat to them feeling more comfortable and having less concern about making mistakes. This finding is in line with Karakis (2020) and Teimouri, Goetze and Plonsky (2019) who found a negative and close relationship between anxiety levels and learning achievement. However, it differed from Zheng and Cheng (2018) as they did not find FLA to significantly affect language performance. Based on the affective filter hypothesis, a lower affective filter enables better learning achievement (Ellis, 2012; Krashen, 1981).

This is also in accord with Gregersen's (2003) observation that anxious students made more errors in their performance. 


\section{Conclusion}

This study found that chat environment played a crucial role in learners' performance. Specifically, SVC environment is found beneficial in reducing Chinese EFL learners' speaking anxiety and improving their speaking performance. This is because students felt relatively comfortable, relaxed and less anxious in performing a dialogue. They did not feel the pressure to give immediate feedback, and this released them from fears that hinder vocabulary production and fluency. Therefore, it would be helpful for language instructors and users to utilize SVC communication mode both inside and outside the classroom, rather than simply depending on F2F interactions in the classroom.

It should be noted that the sample size of this study is relatively small and the participants are mainly females. Therefore, future studies could involve more participants and recruit an equal number of male and female participants. It would also be interesting to explore the effects of different types of groups on learners' speaking performances and anxiety levels in both F2F and SVC platforms. For example, future research could carry out large group discussions or include chats between EFL students and native English speakers.

\section{Declaration of Competing Interest}

None declared.

\section{References}

Andújar-Vaca, Alberto, \& Cruz-Martínez, Maria-Soledad. (2017). Mobile instant messaging: Whatsapp and its potential to develop oral skills. Comunicar, 25(50), 43-52. https://doi.org/10.3916/C50-2017-04

Aydın, S. (2018). Technology and foreign language anxiety: Implications for practice and future research. Journal of Language and Linguistic Studies, 14(2), 193-211.

Baralt, Melissa, \& Gurzynski-Weiss, Laura. (2011). Comparing learners' state anxiety during task-based interaction in computer-mediated and face-to-face communication. Language Teaching Research, 15(2), 201-229. https://doi.org/10.1177/0265532210388717

Bueno Alastuey, M.C. (2011). Perceived benefits and drawbacks of synchronous voice-based computer-mediated communication in the foreign language classroom. Computer Assisted Language Learning, 24(5), 419-432. https://doi.org/10.1080/09588221.2011.574639

Bueno-Alastuey, Ma Camino. (2013). Interactional feedback in Synchronous Voice-based Computer Mediated Communication: Effect of dyad. System, 41(3), 543-559. https://doi.org/10.1016/j.system.2013.05.005

Burns, A., \& Seidlhofer, B. (2002). Speaking and pronunciation. In N. Schmitt (Ed.), An introduction to applied linguistics (pp. 211-232). Arnold.

Cakici, D. (2016). The correlation among EFL learners' test anxiety, foreign language anxiety and language achievement. English Language Teaching, 9(8), 190 -203. https://doi.org/10.5539/elt.v9n8p190

Chew, S. Y., \& Ng, L. L. (2021). Personality and language proficiency on ESL learners' word contributions in face-to-face and synchronous online forums. Journal of Nusantara Studies, 6(1), 199-221. http://dx.doi. org/10.24200/jonus.vol6iss1pp199-221

Creswell, J. W., \& Guetterman, T. C. (2019). Educational research: Planning, conducting, and evaluating quantitative and qualitative research. Pearson.

Ellis, R. (2012). Language teaching research and language pedagogy. John Wiley \& Sons. https://doi. org/10.1002/9781118271643

Fitze, M. (2006). Discourse and participation in ESL face-to-face and written electronic conferences. Language Learning \& Technology, 10(1), 67 - 86. http://dx.doi.org/10125/44047

Firmansyah, D., \& Valatansa vegian, E. E. (2019). Improving the students' speaking skill through debate technique. PROJECT (Professional Journal of English Education), 2(6), 891-895. https://doi:10.22460/project. v2i6.p891-895

Gao, C. et al., (2019). Emerging app issue identification from user feedback: Experience on WeChat. In 2019 IEEE/ACM 41st International Conference on Software Engineering: Software Engineering in Practice (ICSE-SEIP) (pp. 279-288). IEEE. http://dx.doi.org/10.1109/ICSE-SEIP.2019.00040

Horwitz, E. K., Horwitz, M. B. \& Cope, J. (1986). Foreign language classroom anxiety. The Modern Language 
Journal, 70(2), 125-132. https://doi.org/10.1111/j.1540-4781.1986.tb05256.x

Horwitz, E. K. (2001). Language anxiety and achievement. Annual Review of Applied Linguistics, 21, 112-126. https://doi.org/10.1017/S0267190501000071

Horwitz, E. K. (2010). Foreign and second language anxiety. Language Teaching, 43(2), 154-167.

Hughes, A. (2003). Testing for language teachers (2nd ed.). Cambridge University Press. https://doi.org/10.1017/ S026144480999036X

Jaramillo Chérrez, N. V. (2007). A case study of the impact and usefulness of synchronous voice chat to improve EFL learners' spoken production [Unpublished master's thesis]. Iowa State University.

Jasim, W. H., \& A. F. AbuSeileek (2015). Using text and voice chat modes to enhance students' performance in discourse functions. International Journal of Learning Technology, 10(2), 114-136. https://doi.org/10.1504/ IJLT.2015.070685

Jepson, K. (2005). Conversations and negotiated interaction in text and voice chat rooms. Language Learning \& Technology, 9, 79-98. http://dx.doi.org/10125/44033

Jung, Y. J. (2018). The role of socially-mediated alignment in the development of second language grammar and vocabulary: Comparing face-to-face and synchronous mobile-mediated communication [Unpublished doctoral dissertation]. Georgia State University.

Kim, N-Y. (2017). Effects of voice-chat conditions on Korean EFL learners' affective factors. Foreign Languages Education, 24(1), 43-66. https://doi.org/10.15334/FLE.2017.24.1.43

Karakis, Ö. (2020). Learner Autonomy and English Language Course Achievement Mediated by Foreign Language Learning Anxiety. Sakarya University Journal of Education, 10(2), 312-335. https://doi.org/10.19126/ suje.638945

Krashen, S. D. (1981). Second language acquisition and second language learning. Pergamon Press.

Landström, P. (2015). Foreign language anxiety among Chinese senior middle school students: A case study [Unpublished doctoral dissertation]. Karlstad University.

Liu, M., \& Jackson, J. (2008). An exploration of Chinese EFL learners' unwillingness to communicate and foreign language anxiety. The Modern Language Journal, 92(1), 71-86. https://doi.org/10.1111/j.15404781.2008.00687.x

MacIntyre, P. D., \& Gardner, R. C. (1991). Language anxiety: Its relationship to other anxieties and to processing in native and second languages. Language learning, 41(4), 513-534. https://doi.org/10.1111/j.1467-1770.1991. tb00691.x

MacIntyre, P. (1995). How does anxiety affect second language learning? A reply to Sparks and Ganschow. The Modern Language Journal, 79(1), 90-99. http://dx.doi.org/10.2307/329395

Mackey, A. \& Gass, S.M. (2015). Second language research: Methodology and design. Routledge. https://doi. org/10.4324/9781315750606

Misqam, N. N., \& Saidalvi, A. (2019). Investigating English language speaking anxiety among Malaysian undergraduate learners. Asian Social Science, 15(1), 1-7. https://doi.org/10.5539/ass.v15n1p1

Namaziandost, E., Razmi, M. H., Hernández, R. M., Ocaña-Fernández, Yo., \& Khabir, M. (2021). Synchronous CMC text chat versus synchronous CMC voice chat: Impacts on EFL learners' oral proficiency and anxiety, Journal of Research on Technology in Education, (0), p.1-18. https://doi.org/10.1080/15391523.2021.1906362

Oruç, E., \& Demirci, C. (2020). Foreign language anxiety and English language achievement in higher education: The mediating role of student engagement. European Journal of Education Studies, 7(3), 199-212. http://dx.doi. org/10.46827/ejes.v0i0.3012

Pichette, F. (2009). Second language anxiety and distance language learning. Foreign Language Annals, 42, 77-93. https://doi.org/10.1111/j.1944-9720.2009.01009.x

Qu, Y., Rong, W., Ouyang, Y., Chen, H., \& Xiong, Z. (2015). Social aware mobile payment service popularity analysis: The case of WeChat payment in China. In Asia-Pacific Services Computing Conference (pp. 289-299). Springer. https://doi.org/10.1007/978-3-319-26979-5_22

Rao,P.S.(2018).The role of teachers in developing speaking skills inEnglishlanguage classrooms.ACADEMICIA:An International Multidisciplinary Research Journal, 8(12), 5-14. https://doi.org/10.5958/2249-7137.2018.00068.X

Ruixue, M., Zejun, M., \& Yijing, W. (2012). An empirical study on speaking proficiency training for Chinese EFL learners.HigherEducation ofSocialScience,2(1),26-31.https://doi.org/10.3968/j.hess.1927024020120201.2640

Salehi, M, \& Marefat, F. (2014). The effects of foreign language anxiety and test anxiety on foreign language test performance. Theory and Practice in Language Studies, 4(5), 931-940. https://doi.org/10.4304/tpls.4.5.931940

Satar, H. M. and N. Özdener (2008). The effects of synchronous CMC on speaking proficiency and anxiety: Text versus voice chat. The Modern Language Journal, 92(4), 595-613. https://doi.org/10.1111/j.1540- 
4781.2008.00789.x

Seferoglu, G. (2007). The effects of synchronous computer mediated communication (SCMC) on English language learners' oral proficiency development. In The Proceedings of the 6th WSEAS International Conference on e-activities (pp. 14-16). Citeseer.

Sukrutrit, P. (2018). Aspects of language learning in voice-based chat rooms. NIDA Journal of Language and Communication, 23(33), 67-96.

Tam, S. S. (2009). Negotiation of meaning in face-to-face and synchronous computer-assisted interactions among ESL undergraduates [Unpublished doctoral dissertation]. Universiti Malaya, Kuala Lumpur.

Teimouri, Y., Goetze, J., \& Plonsky, L. (2019). Second language anxiety and achievement: A meta-analysis. Studies in Second Language Acquisition, 41(2), 363-387. https://doi.org/10.1017/S0272263118000311

Wang, Z. (2014). Developing accuracy and fluency in spoken English of Chinese EFL learners. English Language Teaching, 7(2), 110-118. http://dx.doi.org/10.5539/elt.v7n2p110

Wang, P. \& Roopchund, R. (2015). Chinese students' English-speaking anxiety in asking questions in the MSC TESOL classroom. International Journal of English Language Teaching, 2(2), 1-18. https://doi.org/10.5430/ijelt. v2n2p1

Warschauer, M. (1996). Comparing Face-to-face and electronic communication in the second language classroom. CALICO Journal, 13 (2), 7-26.

$\mathrm{Wu}, \mathrm{L}$. (2015). Investigating social presence in the voice-based chat room and the text-based forum in the Chinese online learning context [Unpublished doctoral dissertation]. University of the West of England.

Yang, Y. T. C., Gamble, J., \& Tang, S.-Y.S. (2012). Voice over instant messaging as a tool for enhancing the oral proficiency and motivation of English as a foreign language learner. British Journal of Educational Technology, 43, 448-464. https://doi.org/10.1111/j.1467-8535.2011.01204.x

York, J., Shibata, K., Tokutake, H., \& Nakayama, H. (2021). Effect of SCMC on foreign language anxiety and learning experience: A comparison of voice, video, and VR-based oral interaction. ReCALL, 33(1), 49-70. https://doi.org/10.1017/S0958344020000154

Zheng, Y., Cheng, L. (2018). How does anxiety influence language performance? From the perspectives of foreign language classroom anxiety and cognitive test anxiety. Language Testing in Asia, 8(13), 1-19. https:// doi.org/10.1186/s40468-018-0065-4 


\section{SPEAKING ANXIETY IN F2F \& SVC}

\section{Appendix}

\section{Focus Group Interview Questions}

1. In your opinion, which chat modes (F2F, SVC) is more helpful for your speakingperformance?

2. What are the speaking challenges that you faced in F2F and SVC chat respectively?

3. How did you feel about your speaking experience in F2F chat?

4. How did you feel about your speaking experience in SVC chat?

5. In which chat modes did you feel less anxious of speaking English? 